\title{
Efficacy and Safety of Misoprostol Vaginal Insert to Induce Labor beyond $40+0$ Weeks of Gestation
}

\section{Catharina Krause1, Christian Rudlowski1 ${ }^{1,2 *}$, Melanie Erices-Leclercq1, David Tenckhoff ${ }^{1}$, Sabine Lubig1}

${ }^{1}$ Department of Obstetrics and Gynecology, Lutheran Hospital, Begisch Gladbach, Germany

${ }^{2}$ University Hospital Bonn, Bonn, Germany

Email: *c.rudlowski@evk.de

How to cite this paper: Krause, C., Rudlowski, C., Erices-Leclercq, M., Tenckhoff, D. and Lubig, S. (2021) Efficacy and Safety of Misoprostol Vaginal Insert to Induce Labor beyond $40+0$ Weeks of Gestation. Open Journal of Obstetrics and Gynecology, 11, 1333-1341.

https://doi.org/10.4236/ojog.2021.1110124

Received: August 30, 2021

Accepted: October 12, 2021

Published: October 15, 2021

Copyright $\odot 2021$ by author(s) and Scientific Research Publishing Inc. This work is licensed under the Creative Commons Attribution International License (CC BY 4.0).

http://creativecommons.org/licenses/by/4.0/

\begin{abstract}
Objective: Misoprostol vaginal insert (MVI) is proven to induce labor by a continuously release of PGE1. Previous reports showed that MVI reduced induction to delivery time as well as active labor time but it also increased uterine tachysystole. Here we attempted to clarify whether MVI is safe and efficient for women with pregnancies $>40$ weeks in a single institute. Methods: This study was performed in Lutheran Hospital Bergisch Gladbach, Germany 2014-2019. A total of 304 women between $40+0$ to $42+0$ weeks underwent labor induction with MVI. Outcomes were: 1) maternal: time from insertion to delivery, interventions, mode of delivery, and uterine tachysystole, 2) neonatal: cord blood $\mathrm{pH}, \mathrm{APGAR}$ scores, and admission to a neonatal clinic. This study ended unexpectedly due to the withdrawal of MVI (Misodel ${ }^{\mathrm{sm}}$ ) in September 2019. Results: 75.7\% ( $n=230)$ of women gave birth within 24 hours after MVI placement. 72.2\% $(\mathrm{n}=140)$ nulliparous women and 81.8\% $(\mathrm{n}=90)$ parous women delivered within 24 hours. In two cases emergency CS was required. $67.8 \%(n=206)$ of women delivered vaginal. $2.3 \%(n=7)$ of cord $\mathrm{pH}$ levels were below 7.10. 3.3\% $(\mathrm{n}=10)$ of newborns were transmitted to a neonatal clinic. Conclusion: MVI is an efficient method to induce labor for pregnant women beyond $40+0$ weeks. However, considering various complications observed (uterine tachysystole and fetal distress leading to a high number of CS), we cannot universally advocate the use of MVI.
\end{abstract}

\section{Keywords}

Misoprostol Vaginal Insert, Induction of Labor, Caesarean Section, Vaginal Delivery 


\section{Introduction}

Induction of labor is a common procedure aiming to balance maternal and perinatal risks as described by Middleton et al., 2018 [1]. In 2017 in Germany, 21.7\% of deliveries have been induced as shown by the German Health Service 2018 [2]. Even though it is an established procedure, it frequently causes controversy regarding indications and safety. Which method to choose depends on several factors that must be taken into consideration.

In 2017, 37.6\% of women in Germany carried their pregnancies beyond $40+0$ weeks of gestation. $33.3 \%$ of those were induced to labor. The tendency to induce labor increases shown by data from German Health Service 2018 [2]. Several studies from Tunon et al., 1990 [3] and Oleson et al., 2003 [4] Tunon et al., 1999 [2], Olesen et al., 2003 [3] have demonstrated that late-term and post-term pregnancies are associated with a risk of perinatal morbidity and mortality.

Thomas et al., 2014 [5] reported from the Cochrane database that Prostaglandins have been proven to induce labor whilst not increasing the rate of cesarean sections (CS) among women with unscarred uterus. Misoprostol is a synthetic prostaglandin $E_{1}$ analogue. Its oral low-dose use is recommended based on the results of multiple randomised trials as described by Kerr et al., 2021 [6]. It is listed by the WHO 2018 [2] in the list of essential drugs for obstetrical use and it is recommended to use for the medical treatment in pregnant women. It is available for oral and vaginal administration. Studies from Wing et al., 2013 [7], Redling et al., 2019 [8], Hokkila et al., 2019 [9], Bolla et al., 2018 [10], Sharp et al., 2019 [11] and Dobert et al., 2018 [12] showed that Misoprostol vaginal insert (MVI) reduces time to vaginal delivery significantly, as well as active labor even for women with an unfavourable cervix recommended by Schmidt et al., 2019 [13]. Also, the need for oxytocin is reduced compared to dinoprostone vaginal insert or oral misoprostol as showed by Wing et al., 2013 [7], Hokkila et al., 2019 [9] and Eriksson et al., 2020 [14]. Uterine tachysystole is more common in women receiving MVI which was documented by the studies of Wing et al., 2013 [7], Hokkila et al., 2019 [9], Bolla et al., 2018 [10], Schmidt et al., 2019 [13], Mayer et al., 2016 [15]. Currently no studies are available for pregnant women beyond term focussing on the efficacy and safety of MVI.

This study aims to clarify whether MVI is also safe and efficient for women carrying pregnancies beyond $40+0$ weeks.

\section{Materials and Methods}

This single centre study was performed between December 2014 and September 2019 at a tertiary academic centre at the Presbyterian Hospital Bergisch Gladbach, Germany. According to the national guidelines 2014 [15] for pregnancies beyond $40+0$ weeks of gestation with or without additional risk factors induction of labor was recommended. Induction to labor at $40+0$ weeks and beyond were included in this study analysis. Inclusion criteria were age of at least 18 years, uneventful pregnancy as well as unfavourable cervix (BISHOP-score > 4). 
Exclusion criteria were previous CS or uterine scarring, breech-presentation, contraindications for prostaglandins, intrauterine growth restriction, severe preeclampsia, or any signs of high fetal distress.

All women who participated gave informed consent. Local ethic committee reviewed and approved this study. All participants needed hospital admission.

Prior to MVI application a cardiotocography (CTG) assessment for thirty minutes was done. Vaginal examination was performed before the vaginal insert was placed to determine the cervical ripeness. Following the manufacturer's instructions MVI was placed in the posterior vaginal fornix. It contains 200 micrograms in a controlled-release hydrogel polymer system for a single application. According to manufacturer's instructions it must be removed within 24 hours. After 12 hours misoprostol vaginal insert released $50 \%$ of its effective dose. It's biological half-life is 45 minutes. We decided to remove MVI after 12 hours to lower the risk of uterine hyperstimulation. Every four hours CTG assessment was done. MVI was removed either with onset of labor (defined as three or more contractions in ten minutes, lasting $45 \mathrm{~s}$ or longer, and which resulted in cervical ripening), cervical dilatation of four centimetres, tachysystole or after an exposure time of 12 hours maximum.

Primarily we were interested in the time from 1) insertion to onset of labor, 2) onset of labor until delivery and 3) duration from insertion to birth. Secondarily we recorded the mode of delivery, use of epidural anaesthesia as well as the necessity of tocolysis to treat signs of fetal distress defined as any category II or III fetal heartrate pattern. Thirdly we had an interest in neonatal outcome reflected by umbilical artery $\mathrm{pH}$-levels, APGAR scores or admission to a neonatal clinic. Baseline demographic data including age, parity, gestational age, gestational diabetes, and BISHOP scores, among others were collected. The study ended unexpected due to the withdrawal of Misodel ${ }^{\circledR}$ in September 2019. We tested for significance using Wilcoxon-Mann-Whitney-test ( $U$ test). All results were considered significant at p-values $<0.05$. All analysis was performed using SPSS software package version 26 (SPSS Inc., Chicago, IL, and Microsoft ${ }^{\circledR}$ Excel $^{\circledR}$ 2010, version 14 for Windows (Microsoft Corp., Redmond, WA).

\section{Results}

304 pregnant women beyond $40+0$ weeks were included in this prospective cohort study. The median patient age was 33 (range $21-49$ years, Table 1). Weeks of gestation ranged from $40+0$ weeks to $42+0$ weeks (mean $40+5.7$ weeks). Patient's characteristics were listed in Table 1 . When comparing nulliparous and parous women regarding risk factors such as gestational diabetes (GD), preeclampsia or premature rupture of membrane (MR) no significant differences were observed. However, GM and MR were slightly but not significantly more often documented in the patient group beyond $41+0$ weeks of gestation.

$10.9 \%(\mathrm{n}=33)$ lost their MVI. In 45 cases $(14.8 \%)$ MVI failed to induce labour. 
Overall, 75.7\% $(\mathrm{n}=230)$ of women gave birth within 24 hours. After MVI insertion $72.2 \%(n=140)$ nulliparous women and $81.8 \%(n=90)$ parous women gave birth within 24 hours (Figure 1, Table 2). Subgroup analyses revealed that within 24 hours after removal of MVI 259 women out of 304 (85.2\%) delivered their babies. No statistical difference was found between the subgroups of women with $40+0$ to $40+6$ weeks of gestation and women beyond $40+6$ weeks (Table 2).

The median time from (1) insertion to onset of labor was 345 minutes (range 60 minutes to 1440 minutes). 374 minutes was the median time for (2) onset of labor to delivery (range 0 minutes to 3125 minutes) and 750 minutes was median time from (3) insertion to delivery (range 159 minutes to 3361 minutes).

$32.2 \%$ of pregnant women $(n=98)$ required $C S, 41.8 \%(n=83)$ were nulliparous

Table 1. Patient characteristics.

\begin{tabular}{|c|c|c|c|c|c|c|}
\hline & \multirow{2}{*}{$\begin{array}{c}\text { Nulliparous } \\
\mathrm{n}=194 \\
(63.8 \%)\end{array}$} & \multirow{2}{*}{$\begin{array}{c}\text { Parous } \\
\mathrm{n}=110 \\
(36.2 \%)\end{array}$} & \multicolumn{4}{|c|}{$40+0-40+641+0-42+0$} \\
\hline & & & p-Value & $\begin{array}{l}N=153 \\
(50.3 \%)\end{array}$ & $\begin{array}{l}N=151 \\
(49.7 \%)\end{array}$ & $\mathrm{p}$-Value \\
\hline $\begin{array}{c}\text { Age }(y) \\
\text { mean }=32.9\end{array}$ & 31.8 & 34.9 & 0.001 & 32.9 & 33.0 & n.s. \\
\hline $\begin{array}{c}\text { GD } \\
26(8.6 \%)\end{array}$ & $16(8.2 \%)$ & $10(9.1 \%)$ & n.s. & $17(11.1 \%)$ & $9(6.0 \%)$ & n.s. \\
\hline $\begin{array}{c}\text { Preeclampsia } \\
20(6.6 \%)\end{array}$ & $14(7.2 \%)$ & $6(5.5 \%)$ & n.s. & $13(8.5 \%)$ & $7(4.6 \%)$ & n.s. \\
\hline $\begin{array}{c}\text { MR } \\
38(12.5 \%)\end{array}$ & $25(13.0 \%)$ & $13(11.8 \%)$ & n.s. & $18(11.8 \%)$ & $20(13.2 \%)$ & n.s. \\
\hline $\begin{array}{c}\text { Birthweight (g) } \\
\text { mean (SD) }\end{array}$ & $\begin{array}{l}3656.5 \\
(399.4)\end{array}$ & $\begin{array}{l}3597.8 \\
(429.7)\end{array}$ & n.s. & $\begin{array}{l}3546.3 \\
(385.9)\end{array}$ & $\begin{array}{l}3596.9 \\
(433.6)\end{array}$ & n.s. \\
\hline
\end{tabular}

Abbreviations: $\mathrm{GD}=$ Gestational Diabetes, $\mathrm{MR}=$ Membrane Rupture, n.s. = not significant.

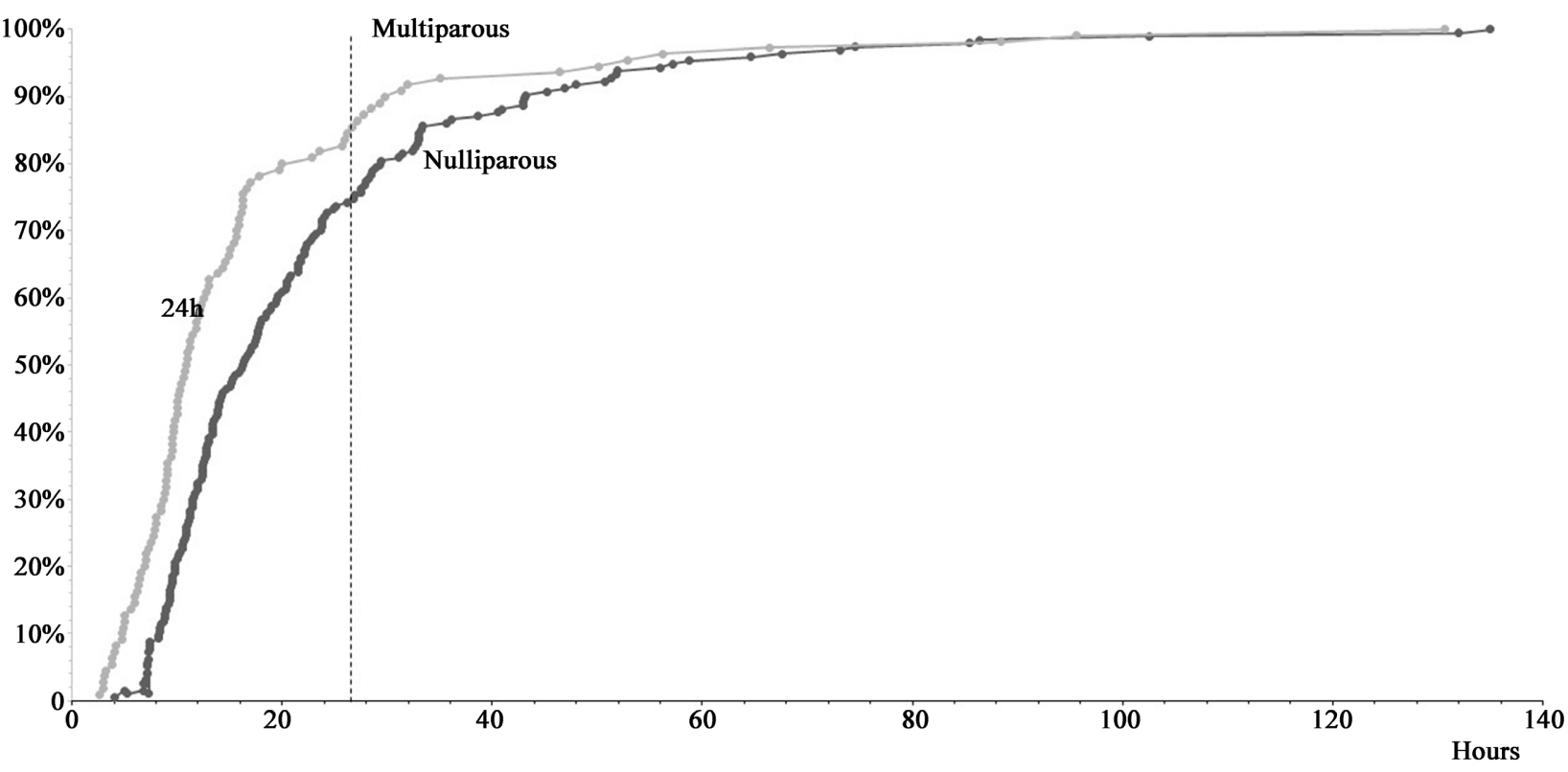

Figure 1. Duration from MVT insertion to delivery in nulli- and multiparous. 
Table 2. Efficacy and safety.

\begin{tabular}{|c|c|c|c|c|c|c|}
\hline & $\begin{array}{c}\text { Nulliparous } \\
\mathrm{n}=194(63.8 \%)\end{array}$ & $\begin{array}{l}\text { Parous } \mathrm{n}=110 \\
\quad(36.2 \%)\end{array}$ & $\mathrm{p}$-Value & $\begin{array}{c}40+0-40+6 \\
n=153 \\
(50.3 \%)\end{array}$ & $\begin{array}{c}41+0-42+0 \\
n=151 \\
(49.7 \%)\end{array}$ & p-Value \\
\hline VB $n=206,(67.8 \%)$ & $111(57.2 \%)$ & $95(86.4 \%)$ & 0.001 & $103(67.3 \%)$ & $103(68.2 \%)$ & n.s. \\
\hline $\mathrm{D} 24 \mathrm{~h} \mathrm{n}=230(75.7 \%)$ & $140(72.2 \%)$ & $90(81.8 \%)$ & n.s. & $117(76.5 \%)$ & $113(74.8 \%)$ & n.s. \\
\hline TTVB $(\mathrm{h})$ mean & 23.0 & 16.9 & n.s. & 22.01 & 19.59 & n.s. \\
\hline $\mathrm{EA} n=121(39.8 \%)$ & $90(46.4 \%)$ & $31(28.2 \%)$ & 0.002 & $54(35.3 \%)$ & $67(44.4 \%)$ & n.s. \\
\hline FI $n=45(14.8 \%)$ & $30(15.4 \%)$ & $15(13.6 \%)$ & n.s. & $28(18.3 \%)$ & $17(11.3 \%)$ & n.s. \\
\hline $\operatorname{CS} n=98(32.2 \%)$ & $83(42.8 \%)$ & $15(13.6 \%)$ & 0.001 & $50(32.7 \%)$ & $48(31.8 \%)$ & n.s. \\
\hline $\operatorname{ECS} n=2(0.6 \%)$ & $2(1.0 \%)$ & 0 & n.d. & 0 & $2(1,3 \%)$ & n.d. \\
\hline Toco $n=32(10.5 \%)$ & $21(10.8 \%)$ & $11(10.0 \%)$ & n.s. & $22(14.4 \%)$ & $10(6.6 \%)$ & 0.03 \\
\hline NA $n=10(3.3 \%)$ & $7(3.6 \%)$ & $3(1.5 \%)$ & n.d. & $6(4.0 \%)$ & $4(2.6 \%)$ & n.d. \\
\hline
\end{tabular}

Abbreviations: VB = Vaginal Birth, D24 h = Delivery within $24 \mathrm{~h}$, TTVB = Time to Vaginal Birth, EA = Epidural Anaesthesia, FI = Failed Induction, CS = Caesarean Section, ECS $=$ Emergency Caesarean Section, Toco $=$ Tocolysis, NA $=$ Neonatal Admission, n.s. $=$ not significant, n.d. $=$ not done

and $13.6 \%(n=25)$ were parous. $42.9 \%(n=42)$ of those showed signs of fetal distress. Other reasons were arrested labor $(45.9 \%, \mathrm{n}=45)$, maternal wish $(8.2 \%$, $\mathrm{n}=8$ ) or placental abruption $1.3 \%(\mathrm{n}=4)$. In two cases emergency CS was required. Tocolysis with fenoterol was necessary in $10.5 \%(n=32)$ of cases (Table 2 ). In our cohort we were able to show that women beyond $41+0$ weeks of gestation received less frequently tocolysis $(6,6 \%$ vs. $14.4 \%) .39 .8 \%(n=121)$ of patients received epidural anaesthesia.

$2.3 \%(\mathrm{n}=7)$ of umbilical artery $\mathrm{pH}$ levels were below $7.10 .0 .3 \%$ had an APGAR score lower than 7 at five minutes. 3.3\% $(n=10)$ of new-borns required transmission to a neonatal clinic.

\section{Discussion}

Pregnant women beyond $40+0$ weeks of gestation form a rather large and sensitive group. According to the American College of Obstetricians and Gynecologists 2014 [16] the likelihood for placental insufficiency is even higher in this cohort. A Cochrane database by Middleton et al., 2020 [18] was able to show an association between induction of labor and a significant perinatal risk reduction for women with prolonged gestation. Furthermore, in day-to-day clinic these women often have a clinical indication for induction of labor or even ask for termination. However, only few data from Wennerholm et al., 2019 [19] were available focussing on safety and efficacy of MVI for this particular group of pregnant women.

According to The American College of Obstetrician and Gynaecologists (ACOG) 2014 [17] MVI is recommended to use to induce labor in pregnant women. It is proven to be reliable and safe to support cervical ripening as showed by Eriksson et al., 2020 [14]. Meanwhile MVI can cause severe uterine tachysystole leading to fetal distress according to the study of Mayer et al., 2016 [15]. 
Our study focuses on pregnant women beyond $40+0$ weeks only. We could demonstrate for the first time that MVI is efficient for induction of labor for those pregnancies. More than 75\% of women achieved vaginal birth within 24 hours. But at the same time, we found a higher rate of CS in comparison to comparable studies. Other studies from Wing et al., 1995 and 2013 [7] [20] for preterm induction of labor reported a CS rate of $16.6 \%-32 \%$. In our cohort with a median duration of $40+6$ weeks the rate of CS was $32.3 \%$. This rate could lead to the conclusion that prolonged pregnancies bear a higher risk for perinatal complications when induced with MVI. Our findings revealed that more than $40 \%$ of CS were clinically indicated due to signs fetal distress while $46 \%$ needed CS because of arrested labor.

Until now literature is controversial regarding rates of CS and fetal outcome after induction with MVI. Research of Dobert et al., 2018 [12] indicated significantly higher CS rates and negative effects on fetal outcome. Sharp et al., 2019 [11] demonstrated increasing CS rates comparing MVI with dinoprostone intravaginal gel. Other studies from Redling et al., 2019 [8], Eriksson et al., 2020 [14] and di Liberto et al., 2014 [21] were able to show that no difference occurred in perinatal outcome and rates of CS comparing MVI to oral misoprostone or dinoprostone insert.

Women with pregnancies beyond $40+0$ weeks are at higher risks for potential placental insufficiency, which could cause fetal distress leading to unfavourable outcomes as reported by Dobert et al., 2018 [12]. Gulmezoglu et al., 2012 [22] summarized in a Cochrane database review that risks for mothers and their unborn babies start to increase significantly after $41+0$ weeks of gestation.

Our results are mainly limited by the monocentric single-arm design. Furthermore, this prospective trial could have had an increased value if we would have had a randomized design contrasting for example other methods of application. In addition, a higher statistical power could be achieved with a larger cohort.

In a recent single arm study Schmidt et al., 2019 [13] and proofed MVI to be efficient to induce woman from $36+0$ weeks of gestation when clinically indicated. They registered uterine tachysystole in almost $25 \%$ as well as fetal heart rate abnormalities in $35 \%$ of cases. The authors suggest to counsel women carefully regarding the risk of uterine tachysystole prior to birth.

In accordance with the manufacturer's guidelines MVI is supposed to be removed at the onset of labor or after 24 hours. Uterine tachysystole after induction with MVI is a common side effect. Women who receive MVI and healthcare professionals who take care of those need to be aware of this fact. Catching the exact moment of onset of labor seems to be crucial to avoid uterine hyperstimulation. In clinical everyday it is sometimes impossible to intervene at the ideal moment. We suggest hospitalisation of women who receive MVI to ensure that they are monitored thoroughly so that in case of hyperstimulation or fetal distress midwives and responsible doctors have the chance to take care of the situation. With this approach we were able to avoid uterine hyperstimulation in most 
cases.

When deciding on which method to choose for induction of labor there is need for an informed decision making. MVI is a very efficient and a fast method to achieve vaginal birth due to its controlled release system. Risks for uterine hyperstimulation is high and the necessity for a rapid birth need to be carefully balanced out. Women should be counselled about benefits and potential risks to be able to make informed choices.

\section{Conclusions}

Looking at our data we conclude as followed:

1) MVI is an effective method to induce cervical ripening to help start labor for pregnant women beyond $40+0$ weeks of gestation.

2) However, due to the unacceptable number of complications such as uterine hyperstimulation leading to a high number of CS, we cannot advocate the use of MVI.

3) Looking at data from the literature, our study was able to show for the first time that a continuously release of misoprostol as a vaginal insert for women beyond 40 weeks of gestation is associated with more complications compared to a repeated oral or vaginal administration of misoprostol.

\section{Conflicts of Interest}

The authors declare no conflicts of interest regarding the publication of this paper.

\section{References}

[1] Middleton, P., Shepherd, E. and Crowther, C.A (2018) Induction of Labour for Improving Birth Outcomes for Women at or beyond Term. Cochrane Database Systematic Review, No. 8, Article No. CD004945.

https://doi.org/10.1002/14651858.CD004945.pub4

[2] Deutsches Gesundheitswesen (2018) Bundesauswertung zum Erfassungsjahr 2017: Geburtshilfe. Institut für Qualitätssicherung und Transparenz im Gesundheitswesen, Berlin.

https://iqtig.org/downloads/auswertung/2017/16n1gebh/QSKH 16n1-GEBH 2017 BUAW V02 2018-08-01.pdf

[3] Tunon, K., Eik-Ne, S.H. and Grottum, P. (1999) Fetal Outcome When the Ultrasound Estimate of the Day of Delivery Is More than 14 Days Later than the Last Menstrual Period Estimate. Ultrasound in Obstetrics and Gynecology, 14, 17-22. https://doi.org/10.1046/j.1469-0705.1999.14010017.x

[4] Olesen, A.W., Westergaard, J.G. and Olsen, J. (2003) Perinatal and Maternal Complications Related to Postterm Delivery: A National Register-Based Study, 19781993. American Journal of Obstetrics and Gynecology, 189, 222-227. https://doi.org/10.1067/mob.2003.446

[5] Thomas, J., Fairclough, A., Kavanagh, J. and Kelly, A.J. (2014) Vaginal Prostaglandin (PGE2 and PGF2a) for Induction of Labour at Term. Cochrane Database Systematic Reviews, No. 6, Article No. CD003101. https://doi.org/10.1002/14651858.CD003101.pub3 
[6] Kerr, R.S., Kumar, N., Williams, M.J., Cuthbert, A., Aflaifel, N., Haas, D.M. and Weeks, A.D. (2021) Low-Dose Oral Misoprostol for Induction of Labor. Cochrane Database Systematic Reviews, No. 6, Article No. CD014484. https://doi.org/10.1002/14651858.CD014484

[7] Wing, D.A., Brown, R., Plante, L.A., Miller, H., Rugar, O. and Powers, B.L. (2013) Misoprostol Vaginal Insert and Time to Vaginal Delivery: A Randomized Controlled Trial. Obstetrics and Gynecology, 122, 201-209. https://doi.org/10.1097/AOG.0b013e31829a2dd6

[8] Redling, K., Schaedelin, S., Huhn, E.A. and Hoesli, I. (2019) Efficacy and Safety of Misoprostol Vaginal Insert vs. Oral Misoprostol for Induction of Labor. Journal of Perinatal Medicine, 47, 176-182. https://doi.org/10.1515/jpm-2018-0128

[9] Hokkila, E., Kruit, H., Rahkonen, L., Timonen, S., Mattila, M., Laatio, L., Ordén, M.-R., Uotila, J., Luukkaala, T. and Tihtonen, K. (2019) The Efficacy of Misoprostol Vaginal Insert Compared with Oral Misoprostol in the Induction of Labor of Nulliparous Women: A Randomized National Multicenter Trial. Acta Obstetricia et Gynecologica Scandinavica, 98, 1032-1039. https://doi.org/10.1111/aogs.13580

[10] Bolla, D., Weissleder, S.V., Radan, A.P., Luisa Gasparri, M., Raio, L., Müller, M., et al. (2018) Misoprostol Vaginal Insert versus Misoprostolvaginal Tablets for the Induction of Labour: A Cohort Study. BMC Pregnancy Childbirth, 18, Article No. 149. https://doi.org/10.1186/s12884-018-1788-Z

[11] Sharp, A., Faluyi, D. and Alfirevic, Z. (2019) Misoprostol Vaginal Insert (Mysodelle) versus Dinoprostone Intravaginal Gel (Prostin) for Induction of Labour. European Journal of Obstetrics and Gynecology and Reproductive Biology, 240, 41-44. https://doi.org/10.1016/j.ejogrb.2019.06.010

[12] Dobert, M., Brandstetter, A., Henrich, W., Rawnaq, T., Hasselbeck, H., Dobert, T.F., Hinkson, L. and Schwaerzler, P. (2018) The Misoprostol Vaginal Insert Compared with Oral Misoprostol for Labor Induction in Term Pregnancies: A Pair-Matched Case-Control Study. Journal of Perinatal Medicine, 46, 309-316. https://doi.org/10.1515/jpm-2017-0049

[13] Schmidt, M., Neophytou, M., Hars, O., Freudenberg, J. and Kühnert, M. (2019) Clinical Experience with Misoprostol Vaginal Insert for Induction of Labor: A Prospective Clinical Observational Study. Archives of Gynecology and Obstetrics, 229, 105-112. https://doi.org/10.1515/jpm-2017-0049

[14] Eriksson, A., Jeppesen, S. and Krebs, L. (2020) Induction of Labour in Nulliparous Women-Quick or Slow: A Cohort Study Comparing Slow-Release Vaginal Insert with Low-Dose Misoprostol Oral Tablet. BMC Pregnancy and Childbirth, 20, Article No. 79. https://doi.org/10.1186/s12884-020-2770-0

[15] Mayer, R.B., Oppelt, P., Shebl, O., Porner, J., Allerstorfer, C. and Weiss, C. (2016) Initial Clinical Experience with a Misoprostol Vaginal Insert in Comparison with a Dinoprostone Insert for Inducing Labor. European Journal of Obstetrics and Gynecology and Reproductive Biolology, 200, 89-93.

https://doi.org/10.1016/j.ejogrb.2016.03.008

[16] Weiss, E., Abele, H., Bartz, C., Franz, M., Fischer, T., Gembruch, U., Gonser, M., et al. (2014) German Guidelines for Indaction of Labor

https://www.awmf.org/uploads/tx szleitlinien/015-0651 S1 Terminüberschreitung Übertragung 02-2014-verlaengert 01.pdf

[17] American College of Obstetricians and Gynecologists (2014) Practice Bulletin No. 146: Management of Late-Term and Postterm Pregnancies. Obstetrics \& Gynecology, 124, 390-396. https://doi.org/10.1097/01.AOG.0000452744.06088.48

[18] Middleton, P., Shepherd, E., Morris, J., Crowther, C.A. and Gomersall, J.C. (2020) 
Induction of Labour at or beyond 37 Weeks' Gestation. Cochrane Database Systematic Reviews, No. 7, Article No. CD004945.

https://doi.org/10.1002/14651858.CD004945.pub5

[19] Wennerholm, U.B., Saltvedt, S., Wessberg, A., Alkmark, M., Bergh, C., Wendel, S.B., Fadl, H., Jonsson, M., Ladfors, L., Sengpiel, V., Wesstrom, J., Wennergren, G., Wikstrom, A.K., Elden, H., Stephansson, O. and Hagberg, H. (2019) Induction of Labour at 41 Weeks versus Expectant Management and Induction of Labour at 42 Weeks (SWEdish Post-Term Induction Study, SWEPIS): Multicentre, Open Label, Randomised, Superiority Trial. British Medical Journal, 367, Article No. 16131.

https://doi.org/10.1136/bmj.16131

[20] Wing, D.A., Jones, M.M., Rahall, A., Goodwin, T.M. and Paul, R.H. (1995) A Comparison of Misoprostol and Prostaglandin $\mathrm{E}_{2}$ Gel for Preinduction Cervical Ripening and Labor Induction. American Journal of Obstetrics and Gynecology, 172, 1804-1810. https://doi.org/10.1016/0002-9378(95)91415-3

[21] di Liberto, A., Endrikat, J., Frohn, S., Solomayer, E. and Ertan, K. (2014) Misoprostol for Pre-Term Labor Induction in the Second Trimester: Role of Medical History and Clinical Parameters for Prediction of Time to Delivery. Journal of Turkish and German Gynecology Association, 15, 130-134. https://doi.org/10.5152/jtgga.2014.13034

[22] Gulmezoglu, A.M., Crowther, C.A., Middleton, P. and Heatley, E. (2012) Induction of Labour for Improving Birth Outcomes for Women at or beyond Term. Cochrane Database Systematic Reviews, No. 6, Article No. CD004945.

https://doi.org/10.1002/14651858.CD004945.pub3 